\title{
AVALIAÇÃO DAS CONDIÇÕES DE SEGURANÇA NO TRABALHO NOS SETORES FLORESTAIS DE UMA INSTITUIÇÃO FEDERAL DE ENSINO SUPERIOR ${ }^{1}$
}

\author{
Amaury Paulo de Souza², Heder Alencar Vianna ${ }^{2}$, Luciano José Minette ${ }^{2}$ e Carlos Cardoso Machado²
}

\begin{abstract}
RESUMO - O objetivo deste trabalho foi analisar os riscos ocupacionais a que se expõem os trabalhadores dos setores florestais de uma Instituição Federal de Ensino Superior do Estado de Minas Gerais, propondo medidas preventivas e corretivas que minimizem ou eliminem tais condições. A análise foi realizada com observações nos ambientes de trabalho e das Comunicações de Acidente em Serviço (CAS), verificando-se alto índice de acidentes no trabalho. Constatou-se a existência de fatores de riscos em todos os setores analisados, destacando o agente físico por ruído, o agente ergonômico por trabalhos com cargas excessivas e o risco de acidentes pelo uso de máquinas perigosas.
\end{abstract}

Palavras-chave: Riscos ocupacionais, Acidente no trabalho e Segurança no trabalho florestal.

\section{EVALUATION OF OCCUPATIONAL SAFETY CONDITIONS IN FOREST SECTORS OF A FEDERAL EDUCATION INSTITUTION}

\begin{abstract}
The objectives of this work were to analyze the occupational risks that the workers of the forest sectors of a federal institution of superior education in Minas Gerais state, Brazil and to propose preventive and corrective measures that minimize or eliminate these conditions. The analysis was accomplished performing observations in work environments and consulting the forms 'Communications of Accident in Service" (CAS). It was observed a high index of work accidents and existence of risks factors in all the analyzed forest sectors. The high noise level was the relevant physical agent followed by the ergonomic risks, heavy loads, and accidents risks by the use of forest machines and equipment.
\end{abstract}

Keywords: Occupational risks, Work accident and Forest work safety.

\section{INTRODUÇÃO}

As exigências sociais implantaram no mundo comercial formas de concorrência nas quais não apenas a qualidade do produto final é considerada relevante para a sua aquisição, sendo inserido, também, como critério de compra, preocupações com os danos ambientais e os riscos a que se expõem os trabalhadores, tema esSe foco principal desta pesquisa.

Aliadas à preocupação com o trabalhador estão as Leis trabalhistas, porém alguns fatores desfavorecem o cumprimento delas, como: dificuldades estruturais e humanas dos órgãos fiscalizadores e a escassez de emprego, fazendo com que o trabalhador se submeta às mais variadas condições laborais.

Fator adverso, também, é a concepção, dos empregadores, de que investimentos em segurança e saúde no trabalho não representam retornos financeiros, prejudicando, assim, as iniciativas prevencionistas aos riscos laborais.

Segundo Porto (2000), a ideia de se preocupar com os problemas de doenças e acidentes de trabalho não deve ser restrita à obediência às normas de segurança

\footnotetext{
${ }^{1}$ Recebido em 31.01.2008 e aceito para publicação em 25.08.2010.

${ }^{2}$ Universidade Federal de Viçosa, UFV, Brasil. E-mail: <amaury@ufv.br>.
} 
e ao fornecimento de equipamentos de proteção individual, mas também em treinamentos, tecnologia e organização do trabalho.

As dificuldades orçamentárias vividas pelas Instituições Públicas de Ensino acarretam limitações às ações administrativas voltadas para a segurança e saúde no trabalho e que representam danos à União, sejam produtivos ou humanos, e que devem ser levados em conta para que se invista mais e melhor nesse quesito.

Somado à preocupação social, Minette (1996) destacou que o ser humano é o principal componente que determina a produtividade, bem como o sucesso ou o fracasso de um sistema de trabalho, o que reitera a necessidade de garantir-lhe um ambiente sadio e seguro.

A má condição do ambiente de trabalho reflete nas qualidades de vida do trabalhador, do produto fabricado e na prestação do serviço executado (SILVA et al., 2002).

De acordo com Machado e Souza (1980), a eliminação de acidentes é de grande importância para o homem. Quando não são fatais, os acidentes, geralmente, têm como resultado as mais variadas lesões corporais.

O objetivo deste estudo foi diagnosticar a situação da segurança e saúde no trabalho em uma Instituição Federal de Ensino Superior, com destaque nos setores florestais, demonstrando a importância de se evitarem acidentes do trabalho e as doenças ocupacionais, propondo medidas preventivas e corretivas para minimizar ou eliminar os riscos a que estão expostos os trabalhadores.

\section{MATERIAL E MÉTODOS}

\subsection{Caracterização do local de estudo}

O estudo foi realizado em Instituição Federal de Ensino Superior, no Estado de Minas Gerais, cuja tabela funcional, em dezembro de 2006, era composta por 795 docentes de ensino superior, 40 docentes de ensino médio e 2.443 servidores técnico-administrativos.

\subsection{População pesquisada}

A população pesquisada envolveu os setores Geração e Distribuição de Vapor, Parques e Jardins, Carpintaria, Marcenaria e Corpo de Bombeiros, que desenvolvem atividades florestais na Instituição, contendo, respectivamente, 9, 67, 18, 24 e 21 trabalhadores com jornada de trabalho de 40 horas semanais.

\subsection{Competência dos setores florestais}

\subsubsection{Geração e distribuição de vapor}

Compete ao Setor a operação de caldeiras a lenha, que fornecem vapor aos alojamentos estudantis, ao restaurante universitário, ao Departamento de Tecnologia de Alimentos e a uma Indústria de laticínios.

\subsubsection{Parques e jardins}

O setor de Parques e Jardins é responsável pela manutenção paisagística da Instituição e pelo manejo de produtos florestais que são consumidos em outros setores, como nas caldeiras, fornecimento de cercas e mourões, andaimes para obras etc.

\subsubsection{Carpintaria}

Entre as atividades do Setor de Carpintaria, citamse a produção de caibros, marcos para portas e janelas; reformas em telhados e outras peças de madeira, reformas em móveis etc. O setor realiza tanto atividades características de carpintaria quanto de marcenaria.

\subsubsection{Marcenaria}

A marcenaria está vinculada ao Laboratório de Propriedades da Madeira do Departamento de Engenharia Florestal, e suas atividades abrangem a confecção de móveis para pesquisas e para uso na Instituição.

\subsubsection{Corpo de bombeiros}

O Setor de Corpo de Bombeiros atende à Instituição e à microrregião do município onde se localiza, e entre suas atividades se destacam: combate a incêndios urbanos e florestais, captura de animais raivosos, corte de árvores que oferecem riscos, queimadas para prevenção etc.

\subsection{Coleta de dados}

A coleta de dados de campo foi realizada no período de outubro de 2006 a fevereiro de 2007, nos ambientes de trabalho dos setores florestais.

\subsection{Identificação dos agentes de risco ocupacional}

A identificação dos agentes de riscos ocupacionais foi feita por meio de análise das Comunicações de Acidentes em Serviço (CAS), identificando os fatores causais dos acidentes; avaliações observativas dos ambientes de trabalho, de forma passiva e com entrevistas aos servidores sobre a percepção dos riscos de suas atividades; e consulta ao Programa de Prevenção de Riscos Ambientais (PPRA) dos ambientes analisados, que oferecem avaliações qualitativas e quantitativas 
dos riscos ambientais e que seguem a identificação e classificação dos agentes de riscos de acordo com as Normas Regulamentadoras da Portaria $n^{\circ}$. 3.214/ 78 (MANUAIS DE LEGISLAÇÃO ATLAS, 2000).

\subsection{Medidas corretivas propostas}

As medidas corretivas propostas foram baseadas em revisões bibliográficas sobre a aplicação de programas voltados para eliminar problemas relacionados à segurança e saúde no trabalho.

\section{RESULTADOS}

\subsection{Avaliações dos riscos ocupacionais nos setores florestais da Instituição}

\subsubsection{Setor de Geração e Distribuição de Vapor}

A Tabela 1 apresenta os principais agentes de riscos ocupacionais observados no Setor com as respectivas medidas preventivas propostas.

\subsubsection{Parques e Jardins}

A Tabela 2 apresenta os principais agentes de riscos ocupacionais observados no Setor de Parques e Jardins, analisados de acordo com as atividades desenvolvidas e as condições de trabalho, com as respectivas medidas preventivas.

\subsubsection{Carpintaria}

A Tabela 3 apresenta os principais agentes de riscos ocupacionais observados no Setor de Carpintaria, analisados de acordo com as atividades desenvolvidas e as condições de trabalho, com as respectivas medidas preventivas.

\subsubsection{Corpo de Bombeiros}

A Tabela 4 apresenta os principais agentes de riscos ocupacionais observados no Setor de Corpo de Bombeiros, analisados de acordo com as atividades desenvolvidas e as condições de trabalho, com as respectivas medidas preventivas.

\subsubsection{Marcenaria}

A Tabela 5 apresenta os principais agentes de riscos ocupacionais observados no Setor, com as respectivas medidas preventivas propostas.

\subsection{Proposição de programas que visem eliminar ou minimizar acidentes e doenças ocupacionais na Instituição}

Para combater as situações de risco no trabalho, apresentam-se, a seguir, alguns programas, e respectivas descrições, que visam minimizar ou eliminar os riscos ocupacionais:

Tabela 1 - Riscos ocupacionais do Setor de Geração e Distribuição de Vapor.

Table 1 - Occupational risks of the Generation and Vapor Distribution Sector.

\begin{tabular}{|c|c|c|c|}
\hline Agentes & Atividades & Possíveis efeitos & Medidas preventivas \\
\hline \multirow[t]{2}{*}{ Físico } & a) Alimentação das caldeiras & a) Desidratação e fadiga pelo calor & $\begin{array}{l}\text { a) Hidratação habitual e rodízio de } \\
\text { operadores }\end{array}$ \\
\hline & b) Trabalhos com motosserra & $\begin{array}{l}\text { b) Danos auditivos e neurológicos } \\
\text { causados pelo ruído e vibração } \\
\text { da máquina }\end{array}$ & $\begin{array}{l}\text { b) Uso de Equipamentos de } \\
\text { Proteção Individual (EPIs) } \\
\text { e exames médicos periódicos }\end{array}$ \\
\hline \multirow[t]{2}{*}{ Químico } & a) Queima da lenha & $\begin{array}{c}\text { a) Intoxicação e asfixia por } \\
\text { fumaça e gases da queima da } \\
\text { madeira }\end{array}$ & $\begin{array}{c}\text { a) Uso de EPIs, queima, } \\
\text { preferencialmente, de madeira } \\
\text { seca e exames médicos periódicos }\end{array}$ \\
\hline & b) Trabalhos com motosserra & $\begin{array}{l}\text { b) Intoxicação por gases } \\
\text { do combustível }\end{array}$ & $\begin{array}{l}\text { b) Uso de EPIs e exames } \\
\text { médicos periódicos }\end{array}$ \\
\hline \multirow[t]{2}{*}{ Ergonômico } & $\begin{array}{l}\text { a) Armazenagem e transporte } \\
\text { manual das toras }\end{array}$ & $\begin{array}{l}\text { a) Fadiga e problemas } \\
\text { osteomusculares }\end{array}$ & $\begin{array}{l}\text { a) Treinamento postural, ginástica } \\
\text { laborativa e limitação do peso } \\
\text { das toras para o transporte }\end{array}$ \\
\hline & b) Trabalhos com motosserra & $\begin{array}{l}\text { b) Fadiga e problemas } \\
\text { osteomusculares }\end{array}$ & $\begin{array}{l}\text { b) Treinamento postural, ginástica } \\
\text { laborativa e pausas em trabalhos } \\
\text { trabalhos de maior esforço físico }\end{array}$ \\
\hline Acidente & $\begin{array}{l}\text { a) Armazenamento e retirada } \\
\text { das toras } \\
\text { b) Trabalho nas caldeiras } \\
\text { c) Transporte manual das toras }\end{array}$ & $\begin{array}{l}\text { a) Ferimento por animais } \\
\text { peçonhentos } \\
\text { b) Explosões das caldeiras } \\
\text { c) Esmagamento de membros } \\
\text { em caso de queda da carga }\end{array}$ & $\begin{array}{l}\text { a) Manter a área sempre limpa } \\
\text { b) Manutenção periódica } \\
\text { c) Uso obrigatório de EPIs e } \\
\text { limitação para o transporte } \\
\text { manual, do peso da carga }\end{array}$ \\
\hline
\end{tabular}


Tabela 2 - Riscos ocupacionais do Setor de Parques e Jardins.

Table 2 - Occupational risks of the Sector of Parks and Gardens Sector.

\begin{tabular}{|c|c|c|c|}
\hline Agentes & Atividades & Possíveis efeitos & Medidas preventivas \\
\hline Físico & $\begin{array}{c}\text { Trabalhos com motosserra } \\
\text { ou motopoda }\end{array}$ & $\begin{array}{c}\text { Danos auditivos e neurológicos } \\
\text { causados pelo ruído e vibração } \\
\text { das máquinas }\end{array}$ & $\begin{array}{c}\text { Uso obrigatório de EPIs } \\
\text { e exames médicos periódicos }\end{array}$ \\
\hline Químico & $\begin{array}{l}\text { a) Aplicação de defensivos } \\
\text { agrícolas } \\
\text { b) Trabalhos com motosserra, } \\
\text { motopoda e pulverizador-costal } \\
\text { mecanizados }\end{array}$ & $\begin{array}{l}\text { a) Intoxicação, irritação e } \\
\text { alergia por agrotóxicos } \\
\text { b) Intoxicação por gases dos } \\
\text { combustíveis }\end{array}$ & $\begin{array}{l}\text { Uso obrigatório de EPIs } \\
\text { e exames médicos periódicos }\end{array}$ \\
\hline Ergonômico & $\begin{array}{l}\text { Trabalhos com motosserra, } \\
\text { motopoda, pulverizadores e } \\
\text { demais ferramentas de campo }\end{array}$ & Fadiga e problemas osteomusculares & $\begin{array}{c}\text { Treinamento postural, ginástica } \\
\text { laborativa e pausas em } \\
\text { trabalhos de maior esforço físico }\end{array}$ \\
\hline \multirow[t]{3}{*}{ Acidente } & $\begin{array}{l}\text { a) Trabalhos com máquinas } \\
\text { e ferramentas }\end{array}$ & $\begin{array}{l}\text { a) Traumatismos, cortes, } \\
\text { esmagamentos ou amputações } \\
\text { de membros e óbito }\end{array}$ & $\begin{array}{c}\text { a) Treinamento, uso de EPIs, } \\
\text { manutenção de máquinas e } \\
\text { adequação de ferramentas }\end{array}$ \\
\hline & b) Atividades de campo & $\begin{array}{l}\text { b) Quedas, picadas de insetos } \\
\text { e de animais peçonhentos }\end{array}$ & b) Uso de EPIs e treinamento \\
\hline & $\begin{array}{l}\text { c) Transporte de servidores } \\
\text { em carrocerias de veículos }\end{array}$ & $\begin{array}{l}\text { c) Danos físicos e óbito em } \\
\text { caso de queda dos veículos }\end{array}$ & $\begin{array}{c}\text { c) Transporte adequado de } \\
\text { servidores e cargas }\end{array}$ \\
\hline
\end{tabular}

Tabela 3 - Riscos ocupacionais do Setor de Carpintaria.

Table 3 - Occupational risks of the Carpentry Sector.

\begin{tabular}{|c|c|c|c|}
\hline Agentes & Atividades & Possíveis efeitos & Medidas preventivas \\
\hline Físico & Trabalho com máquinas & $\begin{array}{c}\text { Danos neurológicos e auditivos } \\
\text { gerados por ruído e vibração } \\
\text { das máquinas }\end{array}$ & $\begin{array}{c}\text { Uso de EPIs, manutenção regular } \\
\text { das máquinas e exames médicos } \\
\text { periódicos } \\
\end{array}$ \\
\hline Químico & $\begin{array}{c}\text { Aplicação de cola fórmica, } \\
\text { selador, cera de carnaúba e verniz }\end{array}$ & $\begin{array}{c}\text { Intoxicações, irritações e } \\
\text { alergias }\end{array}$ & $\begin{array}{c}\text { Uso de máscaras contra } \\
\text { contaminantes químicos e } \\
\text { exames médicos periódicos }\end{array}$ \\
\hline \multirow[t]{2}{*}{ Ergonômico } & a) Transporte manual de madeiras & $\begin{array}{c}\text { Problemas osteomusculares } \\
\text { e fadiga }\end{array}$ & $\begin{array}{c}\text { a) Treinamento postural e } \\
\text { ginástica laborativa }\end{array}$ \\
\hline & b) Postura inadequada nas atividades & & b) Adequação dos postos de trabalho \\
\hline \multirow[t]{4}{*}{ Acidente } & $\begin{array}{c}\text { a) Trabalho com máquinas e } \\
\text { equipamentos }\end{array}$ & $\begin{array}{l}\text { a) Traumatismos, cortes ou } \\
\text { amputações de membros }\end{array}$ & $\begin{array}{l}\text { a) Treinamento, uso obrigatório } \\
\text { proteção e manutenção das }\end{array}$ \\
\hline & b) Armazenamento de serragem & b) Intoxicação e incêndio & $\begin{array}{l}\text { b) Limpeza periódica e } \\
\text { apropriado do material }\end{array}$ \\
\hline & c) Transporte manual de madeira & $\begin{array}{l}\text { c) Esmagamento de membros, } \\
\text { em caso de queda da carga }\end{array}$ & c) Uso obrigatório de EPIs \\
\hline & $\begin{array}{l}\text { d) Movimentação no ambiente } \\
\text { de trabalho }\end{array}$ & $\begin{array}{c}\text { d) Tropeções, quedas e } \\
\text { contusões devido a } \\
\text { obstáculos }\end{array}$ & $\begin{array}{c}\text { d) Organização e limpeza periódica } \\
\text { do ambiente }\end{array}$ \\
\hline
\end{tabular}

- Avaliações de segurança: avaliação periódica nos ambientes de trabalho, com emissões de relatórios, dos diversos fatores de segurança (via check-list), como: Equipamentos de Proteção Individual e Coletiva (EPI e EPC), máquinas, ferramentas, estrutura física etc.

- Campanhas de segurança: programa de sensibilização/conscientização acerca da segurança em assuntos específicos (ex.: trânsito, laboratórios etc.).
- Comitês de segurança: reuniões mensais apresentando os acidentes do mês, bem como suas causas, consequências e ações corretivas e preventivas.

- Diálogo de segurança: reuniões diárias, de curta duração, realizadas antes do início das atividades, a fim de discutir assuntos de segurança e saúde no trabalho, relacionadas com as atividades que irão desempenhar ao longo do dia. 
Tabela 4 - Riscos ocupacionais do Serviço de Corpo de Bombeiros.

Table 4 - Occupational risks of the Fire Department.

\begin{tabular}{|c|c|c|c|}
\hline Agentes & Atividades & Possíveis efeitos & Medidas preventivas \\
\hline \multirow[t]{2}{*}{ Físico } & a) Combate a incêndios & $\begin{array}{l}\text { a) Desidratação e fadiga } \\
\text { por calor e asfixia } \\
\text { pela fumaça }\end{array}$ & a) Hidratação habitual \\
\hline & $\begin{array}{l}\text { b) Combate a incêndios } \\
\text { com água; mergulhos e } \\
\text { salvamento em rios }\end{array}$ & $\begin{array}{l}\text { b) Contaminações, gripes, } \\
\text { resfriados e pneumonias }\end{array}$ & $\begin{array}{l}\text { b) Uso obrigatório de EPIs e } \\
\text { exames médicos periódicos }\end{array}$ \\
\hline \multirow[t]{2}{*}{ Químico } & $\begin{array}{l}\text { a) Salvamento em locais } \\
\text { com concentração de gases }\end{array}$ & a) Intoxicação e asfixia & $\begin{array}{l}\text { Uso de EPIs e exames } \\
\text { médicos periódicos }\end{array}$ \\
\hline & $\begin{array}{l}\text { b) Uso de degermantes para } \\
\text { a limpeza da ambulância }\end{array}$ & b) Irritações e alergias & \\
\hline Biológico & $\begin{array}{c}\text { Contato com socorridos, } \\
\text { animais e rios }\end{array}$ & Doenças contagiosas & $\begin{array}{l}\text { Uso de EPIs e exames } \\
\text { médicos periódicos }\end{array}$ \\
\hline Ergonômico & $\begin{array}{l}\text { Levantamento manual de cargas } \\
\text { ou vítimas, uso de equipamentos } \\
\text { pesados e esforços físicos elevados }\end{array}$ & $\begin{array}{c}\text { Problemas osteomusculares } \\
\text { e fadiga }\end{array}$ & $\begin{array}{l}\text { Adequação de equipamentos, } \\
\text { treinamento postural e } \\
\text { ginástica laborativa }\end{array}$ \\
\hline Acidente & Todas as atividades & $\begin{array}{c}\text { Fraturas, cortes, escoriações, } \\
\text { ataques de animais, queimaduras, } \\
\text { estresse e óbito }\end{array}$ & $\begin{array}{l}\text { Uso de EPIs, treinamento e } \\
\text { e acompanhamento psicológico }\end{array}$ \\
\hline
\end{tabular}

Tabela 5 - Riscos ocupacionais nas atividades da marcenaria.

Table 5 - Occupational risks of the joinery activities.

\begin{tabular}{|c|c|c|c|}
\hline Agentes & Atividades & Possíveis efeitos & Medidas preventivas \\
\hline $\begin{array}{l}\text { Físico } \\
\end{array}$ & Trabalhos com máquinas & $\begin{array}{c}\text { Danos neurológicos e auditivos, } \\
\text { gerados por ruído e vibração } \\
\text { das máquinas }\end{array}$ & $\begin{array}{c}\text { Uso de EPIs, enclausuramento } \\
\text { de máquinas ruidosas, } \\
\text { manutenção e reparo regular } \\
\text { das máquinas e exames } \\
\text { médicos periódicos }\end{array}$ \\
\hline Químico & $\begin{array}{c}\text { Aplicação de cola fórmica, } \\
\text { selador, cera de carnaúba e verniz }\end{array}$ & Intoxicações, irritações e & $\begin{array}{c}\text { Uso de máscaras contra } \\
\text { contaminantes químicos e } \\
\text { médicos periódicos }\end{array}$ \\
\hline \multirow[t]{2}{*}{ Ergonômico } & a) Transporte manual de madeiras & $\begin{array}{l}\text { a) Fadiga e problemas } \\
\text { osteomusculares por } \\
\text { excesso de peso }\end{array}$ & $\begin{array}{l}\text { a) Treinamento postural } \\
\text { e ginástica laborativa }\end{array}$ \\
\hline & b) Pesquisas e trabalhos em bancadas & $\begin{array}{l}\text { s b) Fadiga e problemas } \\
\text { osteomusculares por posturas } \\
\text { inadequadas ou inadequações } \\
\text { ergonômicas }\end{array}$ & $\begin{array}{l}\text { b) Adequação dos postos de } \\
\text { trabalho e treinamento } \\
\text { postura }\end{array}$ \\
\hline \multirow[t]{4}{*}{$\overline{\text { Acidente }}$} & $\begin{array}{l}\text { a) Trabalhos com máquinas e } \\
\text { ferramentas }\end{array}$ & $\begin{array}{l}\text { a) Traumatismos, cortes, } \\
\text { esmagamentos ou amputações } \\
\text { de membros e óbito }\end{array}$ & $\begin{array}{l}\text { a) Treinamento, uso de EPIs, } \\
\text { manutenção de máquinas } \\
\text { e adequação das ferramentas }\end{array}$ \\
\hline & $\begin{array}{l}\text { b) Livre circulação de } \\
\text { pessoas estranhas ao setor }\end{array}$ & b) Acidentes com terceiros & $\begin{array}{c}\text { b) Restrição a servidores ou } \\
\text { pessoas autorizadas a circular } \\
\text { no setor }\end{array}$ \\
\hline & c) Armazenamento de serragem & c) Intoxicação e incêndio & $\begin{array}{c}\text { c) Limpeza periódica e } \\
\text { armazenamento apropriado } \\
\text { do material }\end{array}$ \\
\hline & d) Transporte manual de madeira & $\begin{array}{l}\text { d) Esmagamento de } \\
\text { membros, em caso de } \\
\text { queda da carga }\end{array}$ & d) Uso obrigatório de EPIs \\
\hline
\end{tabular}

- Flash de segurança: retransmissão, ao setores, de informações colhidas nos meios de comunicação, enfocando situações pertinentes à segurança úteis a eles.

- Momento de segurança: realizado mensalmente visando capacitar e conscientizar os funcionários sobre os aspectos relativos à segurança e saúde no trabalho.
- Orientações de segurança: orientações prévias dos riscos e medidas de segurança para usuários que irão adentrar nos ambientes da Instituição.

- Seminários de segurança: evento periódico destinado à atualização, troca de experiências e informações sobre iniciativas voltadas para a saúde e segurança no trabalho. 


\section{DISCUSSÃO}

Este trabalho mostra que em todos os setores analisados há a presença de agentes de riscos ocupacionais influenciados por diversos fatores. Tal constatação sinaliza por haver preocupação para as possíveis consequências sobre os trabalhadores, caso não haja medidas corretivas.

Os riscos ocupacionais, relativos aos agentes físicos, apresentam-se em todos os setores analisados e são oriundos, principalmente, pela presença de ruído originário de máquinas motorizadas. O calor presente nas operações em caldeiras e em combate a incêndios, específico das atividades do Corpo de Bombeiros, também foi um agente constatado.

Segundo Chaib (2005), redução de capacidade auditiva, surdez e alteração no estado emocional são alguns dos efeitos nocivos à saúde a quem se expõe, acima da tolerância, ao ruído. Ainda, segundo esse autor, problemas cardiovasculares, cãibras e insolação são consequências de exposição ao calor.

Os agentes químicos também se mostraram presentes em todos os setores pesquisados e provenientes de diversos fatores, como gases dos combustíveis das máquinas, reagentes químicos usados nas atividades, queima de madeira etc. De acordo com Chaib (2005), efeitos carcinogênicos, teratogênicos, irritantes, asfixiantes, anestésicos e alergizantes, entre outros, são possíveis danos por exposição perigosa a agentes químicos.

O risco biológico é apresentado somente nas atividades do Corpo de Bombeiro por consequente possibilidade de contacto com socorridos, animais e rios. Tal risco pode representar danos por doenças contagiosas, envenenamentos e feridas por animais (PORTO, 2000).

O risco ergonômico, presente em todos os setores observados, evidenciou-se por posturas inadequadas, transporte de cargas com excesso de peso e utilização de máquinas e equipamentos pesados ou ergonomicamente inadequados. De acordo com Porto (2000), tais situações podem acarretar problemas na coluna e dores musculares.

As atividades florestais, por características próprias, já despertam por haver atenção constante no que tange à proteção de seu trabalhador. O risco de acidente é iminente em todas as atividades, tendo em vista a necessidade frequente do uso de diversos tipos e condições de máquinas, ferramentas, equipamentos e ambientes de trabalho.

Autores como Fiedler et al. (2006) sustentaram que ambiente de trabalho inadequado, elevado esforço físico, longa jornada de trabalho, máquinas, ferramentas e equipamentos mal concebidos e baixo nível de satisfação do trabalhador são fatores de agravamento dos riscos de acidentes.

Para eliminar ou diminuir a possibilidade da ocorrência dos danos ocupacionais apontados, tornam-se necessárias a manutenção e adequação de máquinas, ferramentas e equipamentos usados para que se tornem seguros; fornecimento e exigência do uso de equipamentos de proteção individual; oferta de treinamentos laborais; solicitação de exames médicos periódicos; e não possibilidade de desvio de função.

É necessário que haja o entendimento que o comprometimento em ações protetoras à segurança e saúde do trabalhador proporciona benefícios a todos os envolvidos na relação de trabalho e que esse fator não deve ser visto apenas como visão econômica, mas, principalmente, como de caráter humano e social.

Tendo em vista este estudo ter mostrado a diversidade de riscos ocupacionais nas atividades florestais em uma Instituição Federal de Ensino Superior, tornam-se relevantes novas pesquisas, como a análise dos custosbenefícios dos investimentos voltados para a segurança e saúde do trabalhador, pois o melhor entendimento dessas questões poderá contribuir para o estabelecimento de programas de prevenção e políticas públicas.

\section{CONCLUSÃO}

Constatou-se, por intermédio dos resultados, que o trabalho florestal na Instituição é caracterizado pela existência de diversos fatores de riscos ocupacionais, agravados, principalmente, por condições de trabalho inadequadas, como máquinas e equipamentos ultrapassados, ausência de equipamentos de proteção individual, pouco treinamento ou reciclagem do trabalhador e não realização de exames médicos periódicos.

Em relação aos riscos laborais observados nos ambientes e atividades dos setores florestais, pôde-se constatar a existência, em quase todos, de riscos ocupacionais iminentes, com destaque para os agentes físicos, ergonômicos e de acidentes. 
A adoção dos programas propostos na pesquisa é de suma importância, além do que, na maioria dos casos, se trata de programas de simples aplicação e que buscam incrementar a produtividade devido ao ganho em assiduidade, motivação e bem-estar dos trabalhadores.

\section{AGRADECIMENTOS}

À Fundação de Amparo à Pesquisa do Estado de Minas Gerais (FAPEMIG), pelo financiamento do Projeto de Pesquisa intitulado "Desenvolvimento de um sistema de gestão da segurança e saúde no trabalho para as atividades florestais na Universidade Federal de Viçosa”, do qual esta pesquisa é fruto.

\section{REFERÊNCIAS}

CHAIB, E. B. D. Proposta para implementação de sistema de gestão integrada de meio ambiente, saúde e segurança no trabalho em empresas de pequeno e médio porte: um estudo de caso da indústria metal-mecânica. 2005. 126f. Dissertação (Mestrado em Ciências e Planejamento Energético) - Universidade Federal do Rio de Janeiro, Rio de Janeiro, 2005.
FIEDLER, N. C. et al. Avaliação dos riscos de acidentes em atividades de poda de árvores na arborização urbana do distrito federal. Revista Árvore, v.30, n.2, p.223-233, 2006.

MACHADO, C. C.; SOUZA, A. P. Segurança no trabalho com motosserras. Viçosa, MG: Universidade Federal de Viçosa, 1980. 10p.

MANUAIS DE LEGISLAÇÃO ATLAS. Segurança e Medicina do Trabalho. 50.ed. São Paulo: ATLAS, 2000.

MinetTe. L. J. Análise de fatores operacionais e ergonômicos na operação de corte florestal com motosserra. 1996. 211f. Tese (Doutorado) Universidade Federal de Viçosa, Viçosa, MG, 1996.

PORTO, M. F. S. Análise de riscos nos locais de trabalho: conhecer para transformar. São Paulo: Kingraf, 2000. 42p.

SILVA, K. R. et al. Avaliação do perfil de trabalhadores e das condições de trabalho em marcenarias no município de Viçosa-MG. Revista Árvore, v.26, n.6, p.769-775, 2002. 